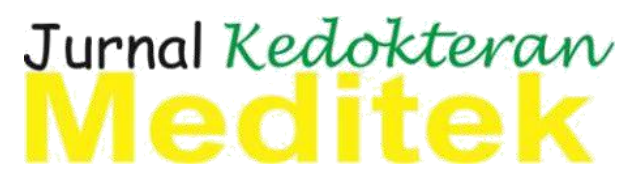

p-ISSN : 2686-1437

e-ISSN : 2686-0201

http://ejournal.ukrida.ac.id/ojs/index.php/Meditek/index

\title{
Perbandingan Tingkat Kontaminasi Kultur Mycobacterium tuberculosis pada Medium Lowenstein-Jensen dan BACTEC MGIT 960
}

\author{
Athira Presialia ${ }^{1}$, Ariyani Kiranasari ${ }^{2}$ \\ ${ }^{1}$ Fakultas Kedokteran Universitas Indonesia \\ ${ }^{2}$ Departemen Mikrobiologi Klinik Fakultas Kedokteran Universitas Indonesia \\ Alamat Korespondensi: athira.presialia@gmail.com
}

\begin{abstract}
Abstrak
Sampai saat ini, kultur masih merupakan standar pemeriksaan diagnosis tuberkulosis. Metode yang sering dilakukan adalah menggunakan Medium Lowenstein-Jensen dan BACTEC MGIT 960, namun kontaminasi oleh bakteri lain maupun jamur dapat terjadi dan dapat mengganggu hasil interpretasi. Penelitian ini bertujuan untuk mengetahui perbandingan tingkat kontaminasi kultur Mycobacterium tuberculosis pada Medium Lowenstein-Jensen dan BACTEC MGIT 960. Penelitian ini menggunakan desain studi potong lintang dengan 204 sampel dari Laboratorium Mikrobiologi Klinik FKUI-RSCM yang memenuhi kriteria penelitian. Data dianalisis menggunakan uji McNemar untuk data komparatif kategorik berpasangan. Dari 204 subjek yang memberikan bahan kultur, mayoritas berada pada rentang usia 26-35 tahun (34,3\%) dan merupakan laki-laki (62,8\%). Dari hasil uji McNemar, didapatkan tidak adanya perbedaan yang signifikan antara tingkat kontaminasi pada medium LJ dan BACTEC MGIT 960 ( $\mathrm{p}=1,000)$. Proporsi hasil kultur positif pada medium LJ dan BACTEC MGIT 960 juga tidak menunjukkan adanya perbedaan yang signifikan $(\mathrm{p}=1,000)$. Tidak ada perbedaan proporsi tingkat kontaminasi pada medium LJ dan BACTEC MGIT 960.
\end{abstract}

Kata kunci: BACTEC MGIT 960, Lowenstein-Jensen, Mycobacterium tuberculosis, tingkat kontaminasi

\section{Comparison of the Contamination Rate between Lowenstein-Jensen Media and BACTEC MGIT 960 as a Culture Method for Mycobacterium tuberculosis}

\begin{abstract}
Culture remains the gold standard for tuberculosis diagnostic testing. Lowenstein-Jensen and BACTEC MGIT 960 are two mediums that are recently used; unfortunately, contamination by other bacteria or fungal may interfere with the interpretation of results. This study aims to compare the contamination rate between Lowenstein-Jensen media and BACTEC MGIT 960. This is a cross-sectional study with 204 samples from the Clinical Microbiology Laboratory of FKUI-RSCM which met the research criteria. Data were analyzed using McNemar test for paired proportion data. Out of the 204 subjects that provided the culture material, the majority were male $(62,8 \%)$ in the 26 to 35 years age group (34,3\%). Based on McNemar test, there was no significant difference of contamination rate between LJ media and BACTEC MGIT 960 ( $p=1.000)$. A significant difference in the proportion of positive culture result between samples cultivated with LJ media and BACTEC MGIT 960 was not found $(p=1.000)$. In conclusion, there was no significant difference in contamination rate between LJ media and BACTEC MGIT 960.
\end{abstract}

Keywords: BACTEC MGIT 960, contamination rate, Lowenstein-Jensen, Mycobacterium tuberculosis

How to cite this article :

Presialia A, Kiranasari A. Comparison of the Contamination Rate between Lowenstein-Jensen Media and BACTEC MGIT 960 as a Culture Method for Mycobacterium tuberculosis. JKdoktMeditek;26(2):36-42. Available from: http://ejournal.ukrida.ac.id/ojs/index.php/Meditek/article/view/1829. DOI: https://doi.org/10.36452/jkdoktmeditek.v26i2.1829 


\section{Pendahuluan}

Tuberkulosis (TB) merupakan salah satu penyakit tertua yang masih menjadi permasalahan kesehatan terbesar di dunia. Menurut WHO Global Tuberculosis Report 2015, pada tahun 2014 terdapat 9,6 juta kasus tuberkulosis di dunia; 5,4 juta terjadi pada pria, 3,2 juta terjadi pada wanita, dan satu juta terjadi pada anak-anak. ${ }^{1}$ Selain itu, terdapat $36 \%$ kasus yang masih belum didiagnosis dan belum dilaporkan. $58 \%$ dari 9,6 juta kasus tuberkulosis di dunia terjadi di wilayah Pasifik Barat dan Asia Tenggara. ${ }^{1}$ Indonesia kini menempati urutan kedua kasus tuberkulosis terbanyak di dunia, yaitu dengan jumlah insidensi sebesar $10 \%$ dari total kasus di dunia. ${ }^{1}$

Tuberkulosis merupakan penyakit infeksi yang dapat dicegah dan disembuhkan. Tingginya insidensi TB di Indonesia memerlukan diagnosis yang akurat serta cepat, sehingga terapi yang adekuat dapat segera ditentukan. ${ }^{2}$ Berdasarkan Pedoman Nasional Pengendalian TB tahun 2011 yang diterbitkan oleh Kementerian Kesehatan, diagnosis TB paru dilakukan dengan pemeriksaan dahak secara mikroskopis. ${ }^{3}$ Pemeriksaan ini merupakan metode yang paling sederhana, cepat, dan paling murah. ${ }^{3}$ Namun, sampai saat ini baku emas untuk pemeriksaan TB adalah kultur. Kultur memberikan hasil yang lebih sensitif daripada pemeriksaan apusan mikroskopis. ${ }^{2,3}$ Metode kultur yang biasa digunakan menggunakan medium padat yaitu Lowenstein-Jensen (LJ). ${ }^{5} \quad$ Medium LJ membutuhkan waktu yang lama (8 minggu) untuk mendiagnosis. Terdapat pula medium cair, seperti Mycobacterial Growth Indicator Tube (MGIT) yang lebih cepat dan sensitif (42 hari) dalam mendeteksi M. tuberculosis. ${ }^{5}$

Dalam melakukan kultur bakteri, kontaminasi oleh bakteri lain maupun jamur dapat terjadi dan dapat mengganggu hasil interpretasi. Pada medium LJ, kualitas telur bebek dan $\mathrm{pH}$ air menjadi salah satu faktor terjadinya kontaminasi. Pada BACTEC MGIT 960, kontaminasi dapat terjadi akibat penyimpanan dan transportasi sampel yang kurang baik. Menurut studi yang dilakukan oleh Kassaza et al, ${ }^{4}$ MGIT memiliki tingkat kontaminasi yang rendah. Pada beberapa studi lain, MGIT memiliki tingkat kontaminasi yang lebih tinggi daripada LJ. ${ }^{5-9} \mathrm{Hal}$ ini disebabkan karena BACTEC MGIT 960 merupakan medium cair berbasis kaldu. Selain itu, perbedaan metode dekontaminasi yang dilakukan di tiap laboratorium pemeriksaan juga dapat memberikan hasil yang berbeda.

Terjadinya kontaminasi pada kultur menyebabkan terhambatnya pemeriksaan sehingga perlu dilakukan pengulangan. Pengulangan akan menyebabkan terjadinya keterlambatan dalam mendiagnosis pasien TB dan membutuhkan biaya yang lebih besar. ${ }^{4}$ Sampai saat ini, belum ada penelitian yang membandingkan antara tingkat kontaminasi pada kultur Lowenstein-Jensen dan MGIT di Laboratorium Departemen Mikrobiologi Klinik FKUI-RSCM. Oleh karena itu, peneliti ingin mengetahui perbandingan tingkat kontaminasi pada kultur LJ dan MGIT sebagai media pertumbuhan $M$. tuberculosis di Laboratorium Departemen Mikrobiologi Klinik FKUIRSCM.

\section{Metodologi Penelitian}

Penelitian dilakukan di Laboratorium Departemen Mikrobiologi Klinik FKUI-RSCM dari Desember 2016 - Oktober 2017. Penelitian menggunakan desain penelitian potong lintang dengan mengambil data sekunder dari data hasil kultur dahak pasien suspek TB di Departemen Mikrobiologi Klinik FKUI-RSCM tahun 2014-2016. Pengambilan sampel dilakukan menggunakan metode probability sampling dengan teknik simple random sampling.

Populasi terjangkau adalah pasien suspek TB yang melakukan pemeriksaan kultur di Laboratorium Departemen Mikrobiologi Klinik FKUI-RSCM pada tahun 2014-2016. Sampel penelitian adalah populasi terjangkau yang memenuhi kriteria inklusi dan kriteria eksklusi. Kriteria inklusi yang harus dipenuhi sampel dalam penelitian ini adalah: subjek melakukan pemeriksaan pada rentang tahun 2014-2016, dahak menunjukkan hasil positif pada pemeriksaan BTA, dan dahak dikultur dengan medium LJ dan BACTEC MGIT 960. Kriteria eksklusi pada penelitian ini adalah kultur tidak tercatat pada dokumen dan hasil pemeriksaan BTA negatif. Pada penelitian ini, hasil positif BTA adalah jika ditemukan bakteri dengan kriteria pelaporan hasil berdasarkan IUATLD, yaitu $+1,+2,+3$, termasuk hasil scanty. Kontaminasi dalam penelitian ini adalah pertumbuhan mikrobiologi lain (bakteri, jamur) pada medium yang dilihat secara makroskopis maupun mikroskopis. Hasil 
MOTT pada kultur tidak terhitung sebagai kontaminasi. Teknik kultur dengan medium LJ dilakukan sesuai dengan buku petunjuk teknis pemeriksaan biakan, identifikasi, dan uji kepekaan M. Tuberculosis pada media padat yang diterbitkan oleh Kementerian Kesehatan tahun 2012. ${ }^{3}$ Pengamatan dilakukan secara berkala setiap minggu dan dilakukan pencatatan setiap hasil temuan. Hasil dinyatakan negatif bila tidak ada koloni yang tampak setelah pengamatan selama delapan minggu. Teknik kultur dengan BACTEC MGIT 960 mengacu pada manual yang ditulis oleh Siddqi dan Rusch-Gerdes. ${ }^{10}$ Hasil biakan MGIT positif adalah jika sensor flurosens pada tabung MGIT mendeteksi pertumbuhan $>75$ unit atau terdapat biomassa $10^{5}-10^{6} \mathrm{CFU} / \mathrm{ml}$ medium berdasarkan penggunaan oksigen pada tabung, sedangkan hasil biakan MGIT negatif adalah jika sensor flurosens tidak mendeteksi penggunaan oksigen pada tabung MGIT sebagai penanda tidak adanya pertumbuhan $M$. tuberculosis. Adapun teknik dekontaminasi kultur yang dilakukan pada penelitian ini adalah metode Petroff termodifikasi sesuai yang dijelaskan oleh Kent dan Kubica. ${ }^{11,12}$ Pada metode ini, dahak sebanyak 3-5 mL dihomogenisasi dengan larutan $\mathrm{NaOH} 4 \%$ pada volume yang sama, kemudian disentrifugasi dengan kecepatan 3000 x $g$ selama 15 menit dan hasil endapan dinetralisasi menggunakan 20 mL akuades. ${ }^{11,12}$

Perkiraan besar sampel dihitung menggunakan rumus penelitian analitik komparatif berpasangan dan didapatkan besar sampel sebanyak 204. Variabel bebas pada penelitian ini adalah metode kultur yang terdiri dari medium LJ dan BACTEC MGIT 960. Variabel terikat adalah proporsi tingkat kontaminasi kultur. Data penelitian dianalisis menggunakan perangkat lunak SPSS versi 20. Analisis deskriptif (univariat) dilakukan untuk mencari frekuensi dari tiap kelompok. Analisis bivariat dilakukan dengan menggunakan uji McNemar.

\section{Hasil Penelitian}

Pada penelitian ini, kontaminasi adalah pertumbuhan mikrobiologi lain (bakteri, jamur) pada medium yang dilihat secara makroskopis maupun mikroskopis. Gambaran kontaminasi pada kultur LJ dan MGIT seperti yang ditampilkan pada Gambar 1 dan Gambar 2.

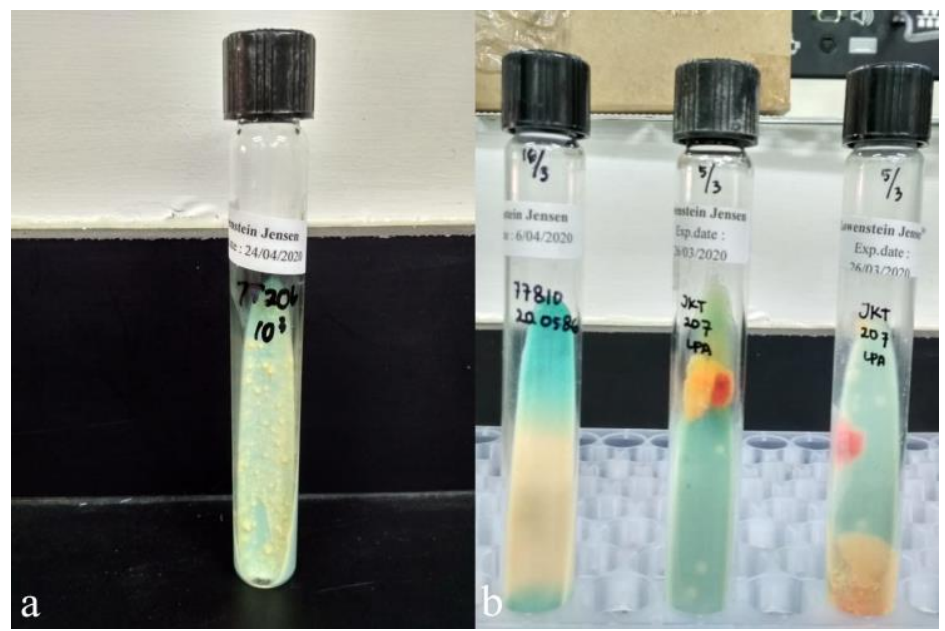

Gambar 1. Medium LJ yang tidak terkontaminasi (a) dan terkontaminasi (b) 


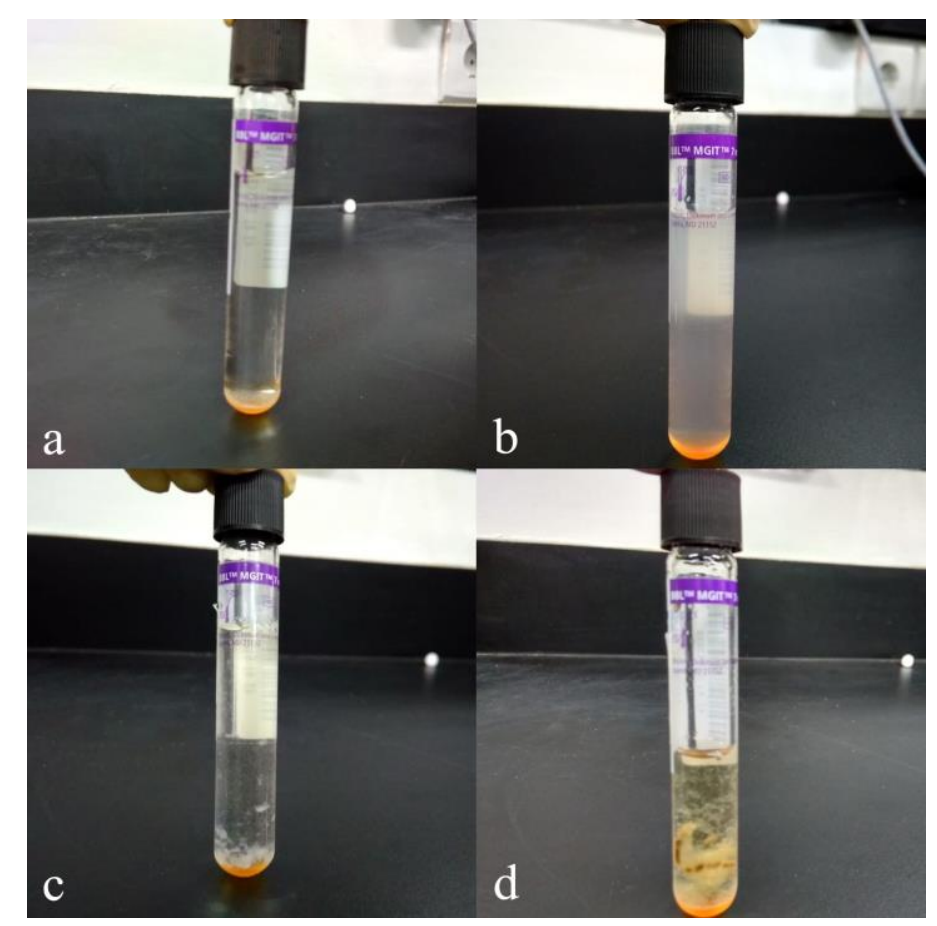

Gambar 2. Medium MGIT yang tidak terkontaminasi (a) dan terkontaminasi (b,c,d)

Tabel 1 menunjukkan perbandingan proporsi tingkat kontaminasi pada sampel yang dikultur dengan medium LJ dan BACTEC MGIT 960, hasil uji McNemar menunjukkan tidak ada perbedaan bermakna $(p>0,05)$. Tabel 2 menunjukkan perbandingan proporsi hasil kultur positif dan negatif pada sampel yang dikultur dengan medium LJ dan BACTEC MGIT 960, hasil uji McNemar juga menunjukkan tidak ada perbedaan bermakna $(\mathrm{p}>0,05)$.

Tabel 1. Perbandingan Tingkat Kontaminasi pada Sampel yang Dikultur dengan Medium LJ dan BACTEC MGIT 960

\begin{tabular}{cccc}
\hline \multirow{2}{*}{ Medium } & $\begin{array}{c}\text { Kontaminasi } \\
n(\%)\end{array}$ & $\begin{array}{c}\text { Tidak Kontaminasi } \\
n(\%)\end{array}$ & $\mathrm{p}$ \\
\hline LJ & $19(9,3 \%)$ & $185(90,7 \%)$ & 1.000 \\
BACTEC MGIT 960 & $19(9,3 \%)$ & $185(90,7 \%)$ & \\
\hline
\end{tabular}

Tabel 2. Perbandingan Proporsi Hasil Kultur Positif dan Negatif pada Sampel yang Dikultur dengan Medium LJ dan BACTEC MGIT 960

\begin{tabular}{cccc}
\hline \multirow{2}{*}{ Medium } & $\begin{array}{c}\text { Positif } \\
n(\%)\end{array}$ & $\begin{array}{c}\text { Negatif } \\
n(\%)\end{array}$ & $\mathrm{p}$ \\
\hline LJ & $175(94 \%)$ & $11(6 \%)$ & 1.000 \\
BACTEC MGIT 960 & $175(94 \%)$ & $11(6 \%)$ & \\
\hline
\end{tabular}




\section{Pembahasan}

Menurut standar CDC, tingkat kontaminasi yang dapat diterima adalah 3-5\% pada medium LJ dan 5-8\% pada medium cair. $^{10,13}$ Tingkat kontaminasi yang sangat rendah $(<3 \%)$ dapat mengindikasikan rendahnya jumlah bakteri yang hidup (bacterial load), yang dapat terjadi akibat proses dekontaminasi yang terlalu keras. Proses ini menyebabkan terganggunya pertumbuhan mikobakterium serta menurunnya angka positivitas. ${ }^{13}$

Hasil penelitian yang dilakukan menunjukkan bahwa baik medium LJ dan BACTEC MGIT 960 memiliki tingkat kontaminasi yang sama tinggi, yaitu sebesar $9,3 \%$. Berdasarkan analisis statistik yang dilakukan menggunakan uji McNemar, hasil menunjukkan tidak adanya perbedaan yang signifikan antara kedua variabel. Adapun hasil proporsi tingkat kontaminasi pada kedua medium memiliki hasil yang berbeda dengan beberapa penelitian sebelumnya.

Beberapa penelitian menunjukkan bahwa proporsi sampel yang mengalami kontaminasi pada BACTEC MGIT 960 lebih tinggi dibandingkan dengan medium LJ. Penelitian yang dilakukan oleh Chihota et al. (2010) menunjukkan proporsi tingkat kontaminasi pada BACTEC MGIT 960 sebesar $15 \%$, sedangkan proporsi tingkat kontaminasi pada medium LJ adalah 9,2\%. ${ }^{5}$ Hasil penelitian yang dilakukan oleh Srisuwanvilai et al. (2008) juga menunjukkan hasil yang berbeda dengan penelitian ini. Hasil penelitian tersebut menunjukkan bahwa proporsi tingkat kontaminasi pada BACTEC MGIT 960 sebesar $12 \%$, medium LJ sebesar 10\%, dan kontaminasi di kedua medium sebesar $2 \% .{ }^{8}$ Hasil penelitian lainnya oleh Diriba et al. (2017) menunjukkan bahwa proporsi tingkat kontaminasi pada BACTEC MGIT 960 sebesar $15 \%$ dan pada medium LJ sebesar 9,3\%. ${ }^{13}$

Terdapat perbedaan antara metode yang dilakukan pada penelitian-penelitian di atas dengan penelitian yang dilakukan di Laboratorium Departemen Mikrobiologi Klinik FKUI-RSCM ini, yaitu dalam teknik dekontaminasi. Metode dekontaminasi yang dilakukan pada penelitian ini adalah metode Petroff termodifikasi. Dahak sebanyak 3-5 mL dihomogenisasi dengan larutan $\mathrm{NaOH} 4 \%$ pada volume yang sama, kemudian disentrifugasi dengan kecepatan $3000 \times \mathrm{x}$ selama 15 menit dan hasil endapan dinetralisasi menggunakan $20 \mathrm{~mL}$ akuades. ${ }^{11}$ Penelitian yang dilakukan oleh Chihota et al. dan Srisuwanvilai et al. menggunakan metode dekontaminasi $\mathrm{N}$-acetylL-cystein-sodium hydroxide (NALC-NaOH) ${ }^{5,8}$ Pada metode ini, setelah dekontaminasi spesimen dinetralisasi menggunakan buffer fosfat dengan $\mathrm{pH}$ 6,8 dan disentrifugasi pada $3000 \times g$ selama 15 menit. Metode ini sesuai dengan yang dijelaskan oleh Kent dan Kubica. ${ }^{11,12}$ Penelitian yang dilakukan oleh Sharma et al. menjelaskan bahwa perbedaan konsentrasi $\mathrm{NaOH}$ yang digunakan dalam dekontaminasi memiliki pengaruh. Metode NALC-NaOH menggunakan konsentrasi $\mathrm{NaOH}$ yang lebih rendah yaitu $2 \%$, sedangkan metode Petroff termodifikasi sebesar 4\%. ${ }^{11,12,14}$

Tingkat kontaminasi yang tinggi (> 8\%) juga dapat dipengaruhi oleh beberapa faktor, seperti dahak yang sangat mukoid, lamanya waktu penyimpanan dan transportasi spesimen, serta penggunaan alat seperti pipet dan tabung yang tidak steril. ${ }^{10}$ Kualitas dahak yang baik ditandai dengan ditemukannya polymorphonuclear neutrophil leukocytes sebanyak >25/LPK dan sel epitel sebanyak $<10 /$ LPK. ${ }^{15}$

Berdasarkan penelitian yang dilakukan, proporsi hasil kultur positif dan negatif pada sampel yang dikultur dengan medium LJ dan BACTEC MGIT 960 memiliki hasil yang sama. Pada Tabel 3, dapat dilihat bahwa 175 sampel (94\%) menunjukkan hasil positif di kedua medium kultur dan 11 sampel (6\%) menunjukkan hasil negatif. Uji McNemar juga menunjukkan tidak adanya perbedaan bermakna yang menyatakan bahwa tidak ada hubungan antara tingkat metode kultur (medium) dengan hasil kultur.

Hasil penelitian yang dilakukan di Laboratorium Departemen Mikrobiologi Klinik FKUI-RSCM ini mendekati hasil dari beberapa penelitian sebelumnya. Penelitian yang dilakukan oleh Lee et al. (2003) di Taiwan melaporkan bahwa proporsi hasil kultur positif pada sampel yang dikultur dengan medium LJ adalah sebesar 92,9\% dan BACTEC MGIT 960 sebesar $100 \% .{ }^{16}$ Penelitian lain oleh Chihota el al. menyatakan bahwa dari 162 sampel yang menunjukkan hasil BTA positif, 151 sampel $(93,2 \%)$ positif pada BACTEC MGIT 960, 144 sampel $(88,9 \%)$ positif pada medium LJ, dan $138(85,2 \%)$ positif pada kedua medium. ${ }^{5}$ Penelitian yang dilakukan oleh Srisuwanvilai et al. menunjukkan hasil proporsi kultur positif 
yang mendekati untuk BACTEC MGIT 960 yaitu sebesar 95\%, namun hasil yang berbeda pada medium LJ yaitu hanya sebesar $79 \% .^{8}$ Penelitian yang dilakukan oleh Chien et al. dengan sampel sputum dan Ma et al. dengan sampel abses juga menunjukkan hasil proporsi kultur positif yang mendekati untuk BACTEC MGIT 960, yaitu sebesar 94\% dan 100\%, namun hasil yang lebih rendah pada medium LJ yaitu sebesar $76 \%$ dan $77,8 \% .^{9,17}$

Di sisi lain, penelitian yang dilakukan oleh Diriba et al. menunjukkan adanya perbedaan. Proporsi kultur positif pada penelitian ini adalah $87,4 \%$ pada BACTEC MGIT 960 dan $66,7 \%$ pada medium LJ. $^{13}$ Perbedaan juga ditemukan pada penelitian yang dilakukan oleh Lawson et al. (2013) di Nigeria, dengan hasil proporsi kultur positif pada BACTEC MGIT 960 sebesar $87 \%$ dan medium LJ sebesar $78 \% .^{18}$

Diriba et al. mengatakan pada penelitiannya bahwa perbedaan temuan antar studi dapat disebabkan oleh berbagai faktor, seperti lamanya paparan dekontaminan, metode dekontaminasi yang terlalu keras, konsentrasi $\mathrm{NaOH}$, komposisi dan kualitas medium, serta kontrol kualitas metode dan laboratorium. Selain itu, status pengobatan pasien juga dapat mempengaruhi hasil. ${ }^{13}$ Penelitian oleh Ma et al. juga mengemukakan bahwa tingginya proporsi hasil kultur positif pada MGIT dapat dipengaruhi karena medium ini mengandung nutrisi yang tinggi yang dapat mempercepat pertumbuhan bakteri, serta sensor fluoresen yang dapat mendeteksi bakteri dalam hasil yang kecil. ${ }^{17}$

Dari hasil penelitian ini, didapatkan bahwa baik medium LJ maupun MGIT memiliki tingkat kontaminasi yang sama tinggi, yaitu sebesar 9,3\%. Kombinasi penggunaan dari kedua media dapat dilakukan agar mendapatkan hasil kultur yang optimal. Selain itu, diperlukan suatu usaha untuk meminimalisir tingkat kontaminasi baik di medium LJ maupun MGIT.

\section{Simpulan}

Berdasarkan hasil dari penelitian yang kami lakukan, dapat disimpulkan bahwa proporsi tingkat kontaminasi, hasil kultur positif dan negatif sampel yang dikultur dengan medium LJ dan BACTEC MGIT 960 menunjukkan tidak adanya perbedaan yang bermakna. Karena pada penelitian ini data yang digunakan merupakan data sekunder, peneliti selanjutnya disarankan terlibat secara langsung dalam proses pengolahan sampel sehingga dapat menentukan turn around time apabila terjadi kontaminasi pada sampel.

\section{Daftar Pustaka}

1. World Health Organization. Global tuberculosis report 2015. Geneva: World Health Organization; 2015.

2. Mertaniasih NM, Alimsardjono L, Palilingan JF, Soedarsono. Rapid culture method using biphasic media on bacteriologic diagnosis to detect mycobacterium tuberculosis for determining pulmonary tuberculosis. Folia Medica Indonesiana. 2013;49(2):916.

3. Sjahrurachman A, Rintiswati N, Gartinah T, Solihin I, et al. Petunjuk teknis pemeriksaan biakan, identifikasi, dan uji kepekaan Mycobacterium tuberculosis pada media padat. Jakarta: Kementrian Kesehatan RI; 2012.

4. Kassaza K, Orikiriza P, Llosa A, Bazira J, Nyehangane D, Page AL, et al. Lowenstein-jensen selective medium for reducing contamination in Mycobacterium tuberculosis culture. J Clin Microbiol. 2014;30;52(7):2671-3.

5. Chihota VN, Grant AD, Fielding K, Ndibongo B, Zyl AV, Muirhead D, et al. Liquid vs solid culture for tuberculosis: performance and cost in a resourceconstrained setting. Int J Tuberc Lung Dis. 2010;14(8):1024-31.

6. Stinson KW, Eisenach K, Kayes S, Matsumoto M, Siddiqi S, Nashima S, et al. Mycobacteriology laboratory manual. $1^{\text {st }}$ ed. Geneva: WHO/GLI; 2014.

7. Somoskovi A, Magyar P. Comparison of the mycobacteria growth indicator tube with MB redox, lowenstein-jensen, and middlebrook 7H11 media for recovery of mycobacteria in clinical specimens. J Clin Microbiol. 1999;37(5):1366-9.

8. Srisuwanvilai L, Monkongdee $\mathrm{P}$, Podewils LJ, Ngamlert K, Pobkeeree V, Puripokai $\mathrm{P}$, et al. Performance of the BACTEC MGIT 960 compared with solid media for detection of mycobacterium in Bangkok, Thailand. Diagnostic microbiology and infectious disease. 2008;61;402-7. 
9. Chien HP, Yu MC, Wu MH, Lin TP, Luh KT. Comparison of the BACTEC MGIT 960 with Lowenstein-Jensen medium for recovery of mycobacteria from clinical specimens. Int $\mathrm{J}$ Tuberc Lung Dis. 2000;4:866-70.

10. Siddqi SH, Rusch-Gerdes S. MGIT procedure manual for BACTEC MGIT 960 TB system. Place Unknown: Foundation for Innovative New Diagnostics; 2006.

11. Sharma M, Misra RN, Gandham NR, Jadhav SV, Angadi K, Wilson V. Comparison of modified petroff's and NAcetyl-L-cysteine-sodium hydroxide methods for sputum decontamination in tertiary care hospital in India. Med J. Dr. D.Y. Patil University. 2012;5(2):97-100.

12. Kent PT, Kubica GP. Public health mycobacteriology. A guide for the level III laboratory. Atlanta: Centers for Disease Control and Prevention; 1985.

13. Diriba G, Kebede A, Yaregal Z, Getahun M, Tadesse M, Meaza A, et al. Performance of mycobacterium growth indicator tube BACTEC 960 with lowenstein-jensen method for diagnosis of Mycobacterium tuberculosis at Ethiopian national tuberculosis reference laboratory, Addis Ababa, Ethiopia. BMC Res Notes. 2017;10(181):1-6.

14. Tripathi K, Tripathi PC, Nema S, Shrivastava AK, et al. Modified Petroff's method: an excellent simplified decontamination technique in comparison with petroff's method. Int J Recent Trends in Science and Technology. 2014;10(3):461-4.

15. Khan MS, Dar O, Tahseen S, GodfreyFaussett P. Judging respiratory specimen acceptability for AFB microscopy: visual vs. microscopic screening. Trop Med Int Health. 2009;14:571-5. 10.1111/j.13653156.2009.02260.x

16. Lee J, Sou J, Lin CB, Wang JD, Lin TY, Tsai YC, et al. Comparative evaluation of the BACTEC MGIT 960 system with solid medium for identification of Mycobacterium. Int $\mathbf{J}$ Tuberc Lung Dis. 2003;7(6):569-74.

17. Ma Y, Fan J, Li S, Dong L, Li Y, Wang F, et al. Comparison of Lowenstein-Jensen medium and MGIT culture system for recovery of mycobacterium tuberculosis from abscess samples. Diagnostic
Microbio and Infectious Disease. 2020;96(4).

10.1016/j.diagmicrobio.2019.114969.

18. Lawson L, Emenyou N, Abdurrahman ST, Lawson JO, Uzoewulu GN, Sogaolu OM, et al. Comparison of Mycobacterium tuberculosis drug susceptibility using solid and liquid culture in Nigeria. BMC Res Notes. 2013;6:215. 